\title{
Design and Performance Research of Flexible Drill Pipe Joint Based on Bionic Theory
}

\author{
Chuanliu Wang $(D)$ and Pei Ju (CD \\ Xi'an Research Institute of China Coal Research Institute, Xi'an 710077, China \\ Correspondence should be addressed to Chuanliu Wang; wangchuanliu@cctegxian.com
}

Received 12 May 2021; Revised 23 June 2021; Accepted 20 July 2021; Published 4 August 2021

Academic Editor: Xudong Zhang

Copyright ( $\odot 2021$ Chuanliu Wang and Pei Ju. This is an open access article distributed under the Creative Commons Attribution License, which permits unrestricted use, distribution, and reproduction in any medium, provided the original work is properly cited.

\begin{abstract}
Fatigue fracture is the main failure form of mining drill pipe joints, which directly leads to the occurrence of drill pipe drop accidents. Based on the principle of engineering bionics, the spine structure and kinematic behavior characteristics of cheetah were studied; the bionic design and trial production of drill pipe joints were carried out. For the bionic drill pipe joint, it separates the torsion transmission function from the connection function, and when the torsion transmission function of the joint fails, the connection function is still effective, so as to achieve the effect of "breaking the bones and connecting the ribs." The mechanical and flow field properties of the bionic drill pipe joint were analyzed. Mechanical test results showed that, for the bionic drill pipe joint, the average tensile capacity was $555.48 \mathrm{kN}$ and the average torsion capacity was $8914.13 \mathrm{~N} \cdot \mathrm{m}$, which met the mechanical performance requirements. The flow field numerical simulation results showed that, when the drilling fluid velocity field and pressure field were stable and change evenly, there is no risk of leakage. The study results can provide a new research idea for the research and development of mine drill pipe joint with long life and antidropping function.
\end{abstract}

\section{Introduction}

Drilling technology is widely used in the fields of gas drainage and water hazard control in coal mines, which is of great significance to the safe production of coal mines. During the drilling process in coal mine, the force of the drill pipe joint is complicated, and due to the limitation of the space size of underground roadway, there has more threaded connections for the drill pipes, which leads to the rigidity of the pipe is strong, and the fracture accidents of the drill pipes occur from time to time [1]. According to statistics, more than $75 \%$ of drill pipe fractures are located at the root of the external thread (as shown in Figure 1). The drill pipe is severely bent in the hole, and stress concentration is likely to occur at the root of the external thread, which leads to the fracture of the drill pipe and the formation of the "drop drilling" accident. When the "drop drilling" accident occurs, it is necessary to carry out fishing operations, which will waste a lot of manpower and material resources and increase the drilling production cycle and cost [2-6]. Therefore, the key to solving the "drop drilling" problem is to solve the problem of the fracture at the root position of the external thread.

To solve the above problem, scholars have proposed many solutions, which can be summarized in three aspects. (1) New materials: research the materials with better comprehensive performance and improve the overall performance of external threads. For example is He who took $4145 \mathrm{H}$ material and $\varphi 88.9 \mathrm{~mm}$ drill pipe joint thread (NC38) as the research object, and he applied the nanocopper antifriction coating AFRICO to the joint thread, so as to achieve the purpose of improving the antisticking performance of the thread [7]. (2) Structural size optimization: optimize the overall structure of drill pipe, especially the size of the thread, and add stress grooves. For example is Tian et al. who studied the strength and sealing characteristics of different thread structures, such as round thread, trapezoidal thread, and partial trapezoidal thread, and they pointed out that the double shoulder thread structure was helpful to protect the overload [8]; Liu et al. proposed a method of setting TLM stress relief groove in the internal thread of the upper joint of drill pipe, 

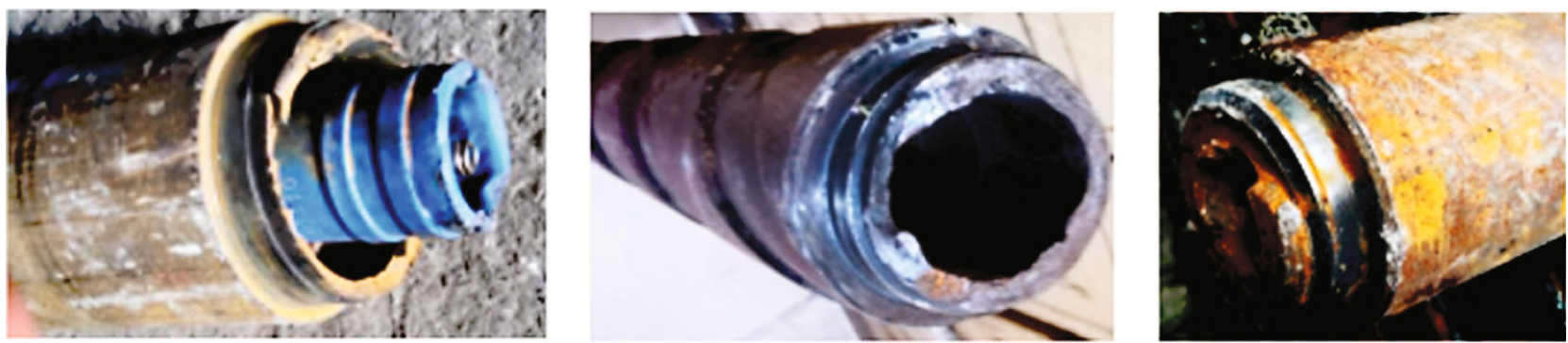

FIgURE 1: Photos of fracture of the external thread of drill pipe.

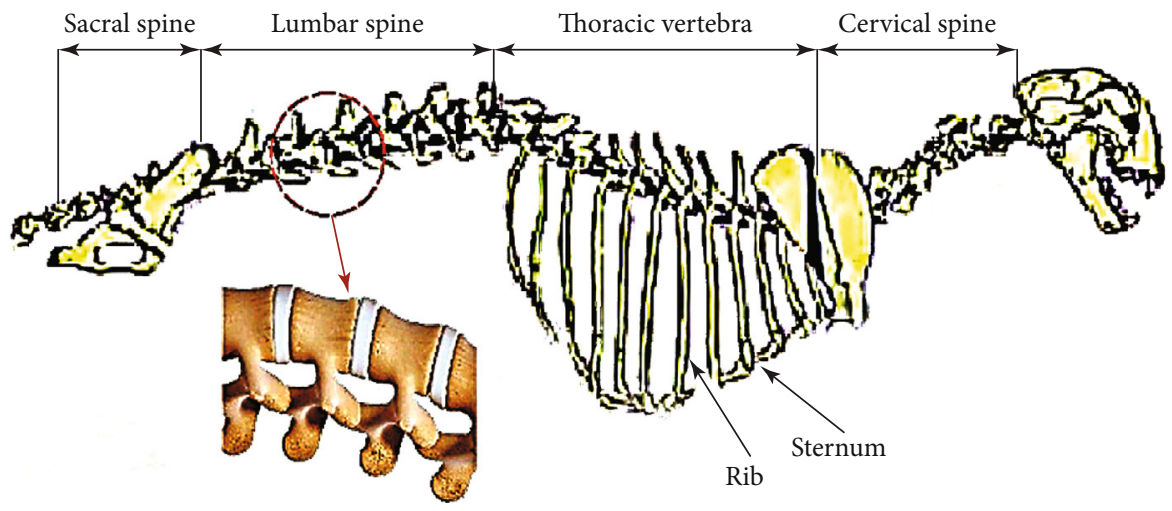

FIgURE 2: Cheetah spine skeleton diagram.

so as to reduce the frequency of drill pipe leakage and thread fracture effectively [9]. (3) New type of thread: develop new tooth profile, optimize thread parameters, perform surface treatment, etc. For example is Gao et al. who designed a new type of V-50R thread profile structure, which can improve the torsional strength of the thread and alleviate the problem of stress concentration by increasing the pitch and side angle of the thread [10]; Dong et al. designed a new type of $\mathrm{W}-038 \mathrm{R}$ thread profile structure, which can reduce the stress concentration at the bottom of the thread by increasing the thread root size and bottom arc radius; finally, the torsion and bending resistance of the thread can be improved [11]. The core of the above measures is to reduce the stress concentration at the root of the external thread, but it does not essentially solve the problem of drill pipe "drop drilling" caused by the fracture of the external thread.

Bionics, as an emerging edge subject arising from the organic combination of biological sciences and technical sciences, can produce unexpected innovations when applied to the field of drilling technology [12-15]. Based on this, inspired by the strong structure of four-legged mammals such as cheetahs, the cheetah spine structure is used as a bionic model, and the drill pipe joint is designed as bionic structure. By using laser cutting and alloy die-casting methods, the drill pipe joint is processed into a combination of three parts: the torsion shoulder, the cushion layer, and the front thread, which can achieve the effect of "breaking the bones and connecting the ribs." By means of laboratory test and numerical simulation, the mechanical and flow filed performance of the bionic drill pipe joint is analyzed, and the reliability of the design is explained, so as to explore a new research idea for solving the problem of drill pipe "drop drilling."

\section{Bionic Design of Drill Pipe Joint}

The spine of the animal is composed of vertebrae and intervertebral discs and is connected by elastic cartilage and ligaments. It is a very soft and flexible structure with multiple degrees of freedom [16]. This paper takes cheetah as the research object and provides a biological prototype for the bionic design of drill pipe joint through the study of its spinal structure and movement behavior characteristics.

2.1. Spinal Structure and Movement Behavior of Cheetah. The spine of cheetah is mainly composed of cervical spine, thoracic spine, and lumbar spine, as shown in Figure 2. The thoracic structure is composed of thoracic spine, sternum, and ribs, which can protect the heart, lungs, and other important organs, so for the thoracic structure, the stiffness is greater. The lumbar spine is more flexible and can carry out up and down, left and right bending and axial torsion movements, so for the lumbar spine structure, the stiffness is relatively small. The vertebrae and intervertebral disc of the cheetah are chimeric with each other, and there are some structural features such as soft connection between elastic cartilage and ligament along the circumferential direction, which can provide inspiration for the bionic design of drill pipe joint $[17,18]$.

In order to describe the movement behavior of cheetah, a movement coordinate system as shown in Figure 3 is established. When the cheetah runs, the curvature of the spine mainly occurs in the lumbar spine, and the motion of the 


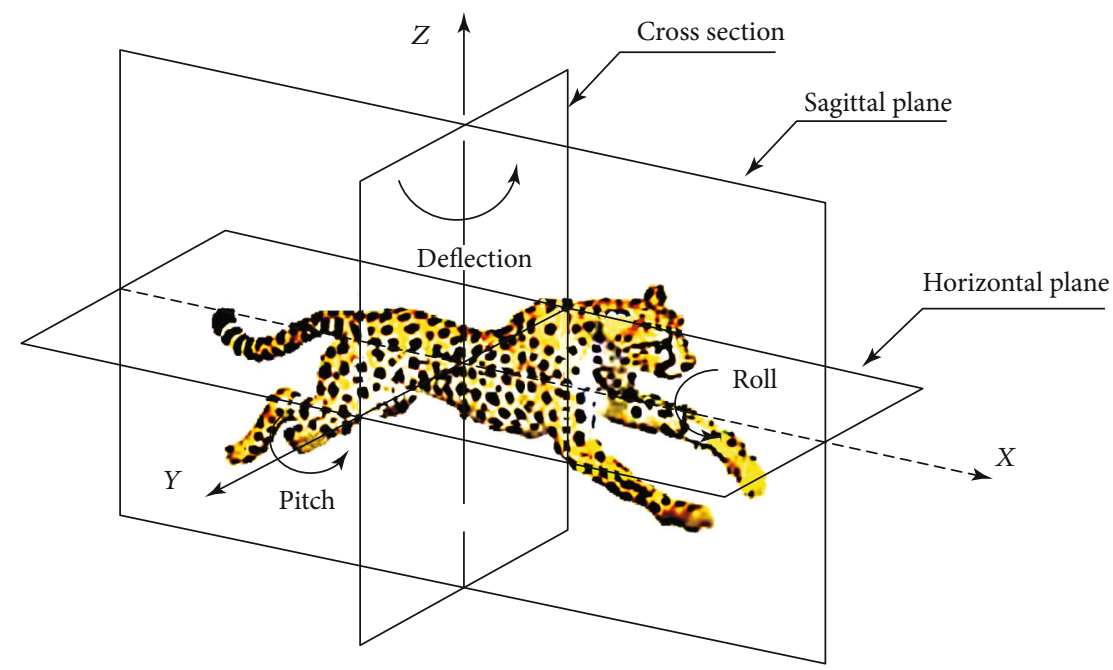

Figure 3: Spine skeleton diagram of cheetah.

second lumbar joint close to the thoracic spine is the largest. When the cheetah runs in a straight line, the curvature of its trunk mainly occurs in the sagittal plane of the spine, while the curvature in the cross section and the horizontal plane is small; when the cheetah runs in a turn, the curvature of the spine mainly occurs in the horizontal plane.

2.2. Mathematical Model of the Movement of Spine. Combining engineering bionics techniques and similar principles, the pseudo-rigid model is used to construct the mathematical model of the cheetah's spine, and by revealing the principle of the strength and toughness of the cheetah spine, provide guidance for the bionic design of the drill pipe joint.

According to the structural characteristics of the spine of cheetah and referring to the anatomical structure parameters such as the length ratio relationship between vertebrae and intervertebral disc, the bionic joint is designed. The bionic joint is composed of multiple combination segments (shown as Figure 4), and each combined segment can be regarded as a mechanical pseudo-rigid body model with 1 pseudo-elastic body and 2 rigid bodies. Assume the width of the pseudoelastic body is $l_{p}$, the width of the rigid body is $l_{g}$, the characteristic radius coefficient of the model is $\gamma$, the vertical load applied to the end of the spine is $F$, and the stiffness of the pseudo-elastic body is $K_{1}, K_{2}, \cdots, K_{n}$. According to the properties of pseudo-elastomeric materials, the characteristic radius coefficient $\gamma$, the parameter angle coefficient $C_{0}$, and stiffness coefficient $K_{0}$ can be obtained by linear interpolation method. The stiffness $H_{i}$ of a certain combined segment can be expressed as follows:

$$
\begin{aligned}
H_{i} & =\left(E+2 G S_{i}^{2}\right) I, \\
S_{i} & =\frac{R}{2 l_{p i}},
\end{aligned}
$$

where $E$ is the Young model of the pseudo-elastomeric material, $G$ is the shear modulus of the pseudo-elastomeric material, $I$ is the inertia of cross-sectional moment of the pseudo-elastomeric body, $S_{i}$ is the shape factor of the $i$ th

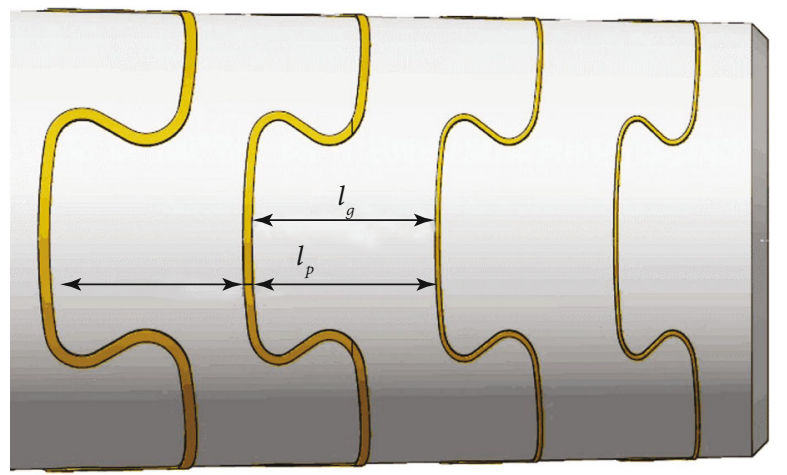

Figure 4: Pseudo-rigid body model of bionic joint.

pseudo-elastomeric body, $R$ is the effective diameter of the spine, and $l_{p i}$ is the thickness of the $i$ th elastomer.

The stiffness of the pseudo-elastic body of each pseudorigid body model is expressed as follows:

$$
K_{i}=\frac{\gamma K_{0} H_{i}}{l_{p i}}
$$

The length of each pseudo-rigid body model is as follows:

$$
\left\{\begin{array}{l}
L_{i}=\gamma l_{p i}+l_{g(i+1)}+(1-\gamma) l_{p(i+1)}, \quad i=1,2, \cdots, n-1, \\
L_{i}=\gamma l_{p i}+l_{g(i+1)}, \quad i=n .
\end{array}\right.
$$

The bending moment balance expression of each pseudorigid body model is as follows:

$$
\left\{\begin{array}{l}
K_{i} \theta_{i}=K_{i+1} C_{\theta} \theta_{i+1}+F L_{i} C_{\theta} \cos \left(\sum_{j=1}^{i} \theta_{j}\right), \quad i=1,2, \cdots, n-1, \\
K_{i} \theta_{i}=F L_{i} C_{\theta} \cos \left(\sum_{j=1}^{i} \theta_{j}\right), \quad i=n,
\end{array}\right.
$$


where $\theta_{i}$ and $\theta_{j}$ are the bending angles of the $i$ th and $j$ th pseudo-elastic bodies, respectively.

By solving Equation (5) numerically, the bending angle of each point can be obtained. Using these angle values, the total deformation of the bionic joint can be calculated as follows:

$$
D=\sum_{i=1}^{n}\left(L_{i} \sin \sum_{j=1}^{i} \theta_{j}\right)
$$

The overall bending stiffness of the bionic joint can also be obtained as follows:

$$
K_{S}=\frac{F}{L}
$$

2.3. Bionic Design of the Structure of Drill Pipe Joint. Based on the above analysis of the characteristics of cheetah spinal structure, the idea of "softness overcoming rigidity" is adopted, the fragile (rigid) part of the root of drill pipe joint is cut into two parts (the torsion shoulder (the " 1 " part shown in Figure 5) and the front thread (the "2" part shown in Figure 5)), and then the cushion (flexible) layer (the " 3 " part shown in Figure 5) is injected into the gap between the torsion shoulder and the front thread; finally, an elastic cartilage and ligament structure of the drill pipe joint which is similar to the spine is formed, as shown in Figure 5.

The existence of the flexible cushion 3 is conducive to absorbing certain deformation, improving the stress state of the drill pipe joint. Stress is distributed evenly along the slit cutting seam (shown as Figure 6), which can avoid the stress concentration, and also, the force of the bionic joint varies with the bending direction of the drill pipe. When the drill pipe joint is stressed heavily, the cushion layer is the first part to be destroyed, so that the broken part of the drill pipe changes from randomness to fixedness. Most importantly, the torque transmission function and the connection function of the drill pipe joint are separated with this bionic structure; when the joint torque transmission function fails, the connection function is still effective, so as to achieve the effect of "breaking the bones and connecting the ribs." The drill pipe still has high tensile strength, and the drill rod can be smoothly lifted out of the hole, thereby completely solving the problem of drill pipe "drop drilling" caused by the fracture of the drill pipe joint.

2.4. Processing of Bionic Drill Pipe Joint. The external joint of the drill pipe is cut along the fragile part on the root of the joint by laser cutting method. The cutting path is petalshaped; the torsion shoulder and the front thread are formed at the joint because of the existence of the slit, and these two parts can be separated but cannot be taken off from each other. Then, the copper-nickel alloy material is filled into the cutting seam by high-temperature die-casting method, the cushion layer is formed, and the width of the cushion layer is between 0.6 and $1.2 \mathrm{~mm}$.

For the filled copper-nickel alloy material, its yield strength is between 50 and $80 \%$ of the yield strength of the joint material, the elongation is not lower than that of the

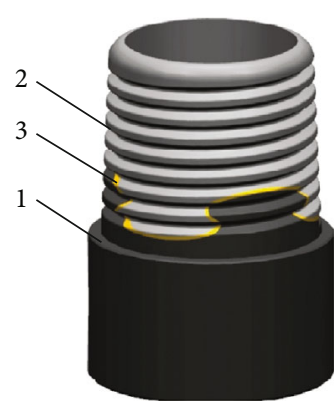

FIgURE 5: Schematic diagram of bionic structure of drill pipe joint.

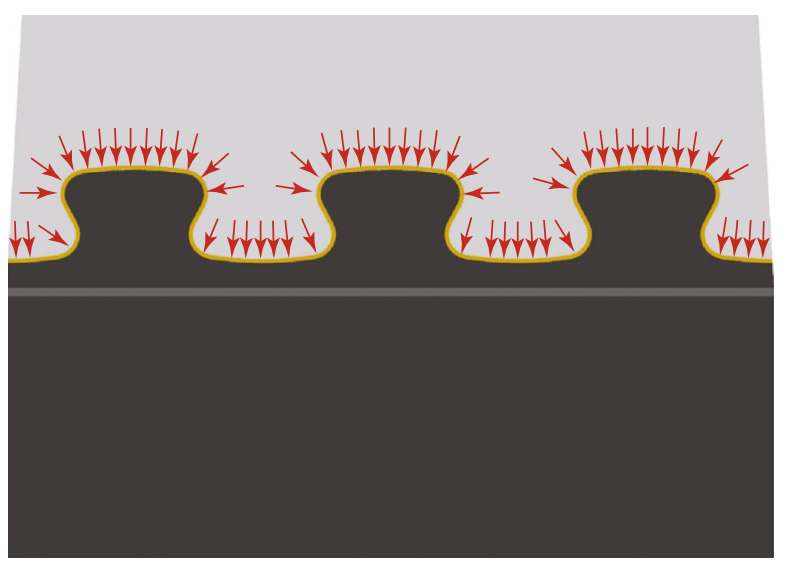

FIGURE 6: Schematic diagram of stress distribution along the slit.
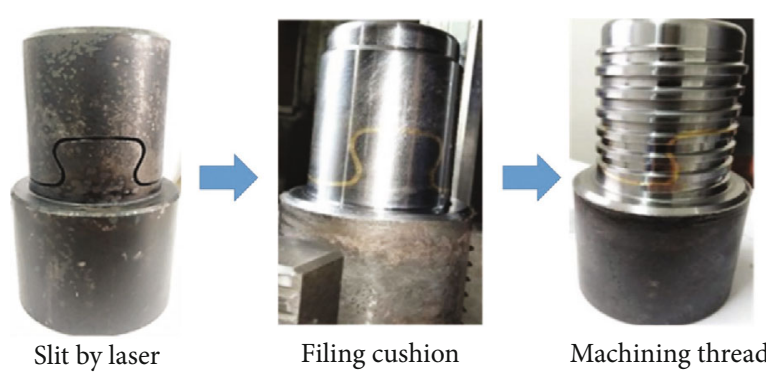

Filing cushion

Machining thread

Figure 7: Processing flow of the bionic drill pipe joint.

joint material, the elastic modulus is between 40 and $60 \%$ of the elastic modulus of the joint material, and it can withstand a certain amount of compression and tension deformation.

Finally, the circular turning and thread finishing are carried out, and nitriding is carried out to improve the hardness and wear resistance of the joint surface. Figure 7 shows the processing flow of the bionic drill pipe joint.

\section{Mechanical Performance of Bionic Drill Pipe Joint}

Based on the above analysis, the bionic drill pipe joint was machined, and the mechanical properties of the bionic drill pipe joint were tested.

3.1. Tensile Performance Testing. After the cutting of the outer joint of the drill pipe was completed, and before the 

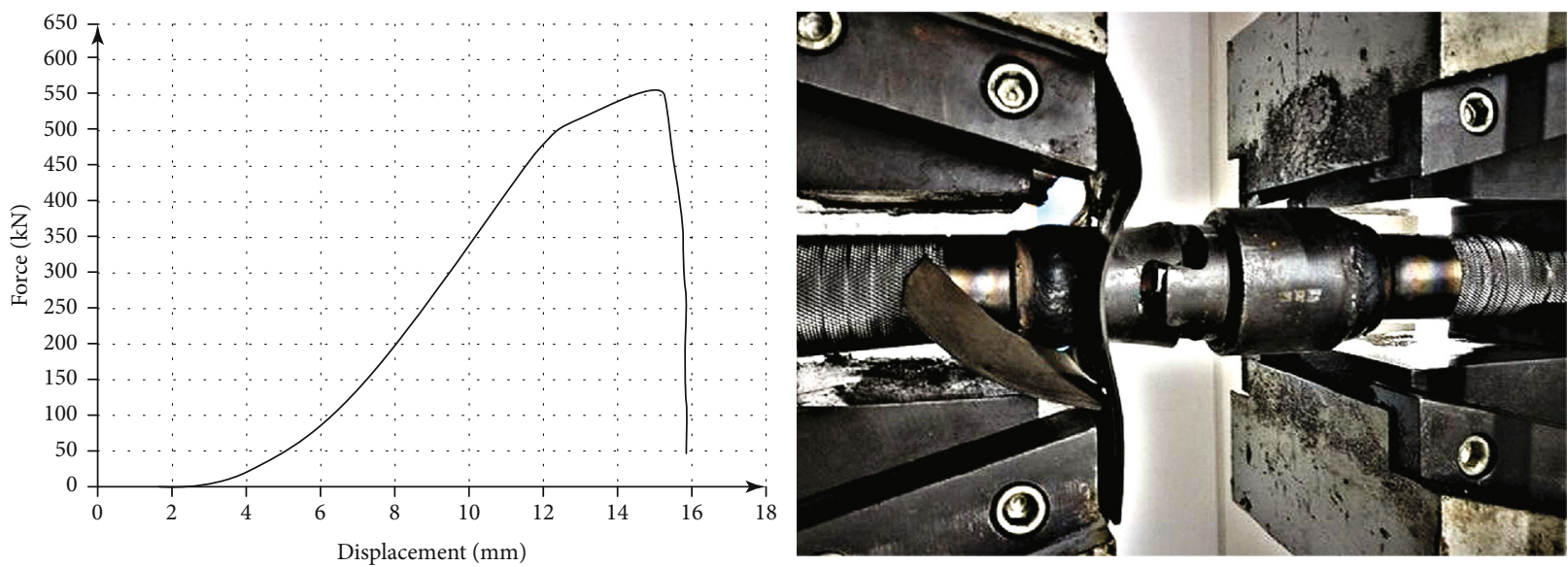

FIGURE 8: Tensile performance test of the bionic drill pipe.
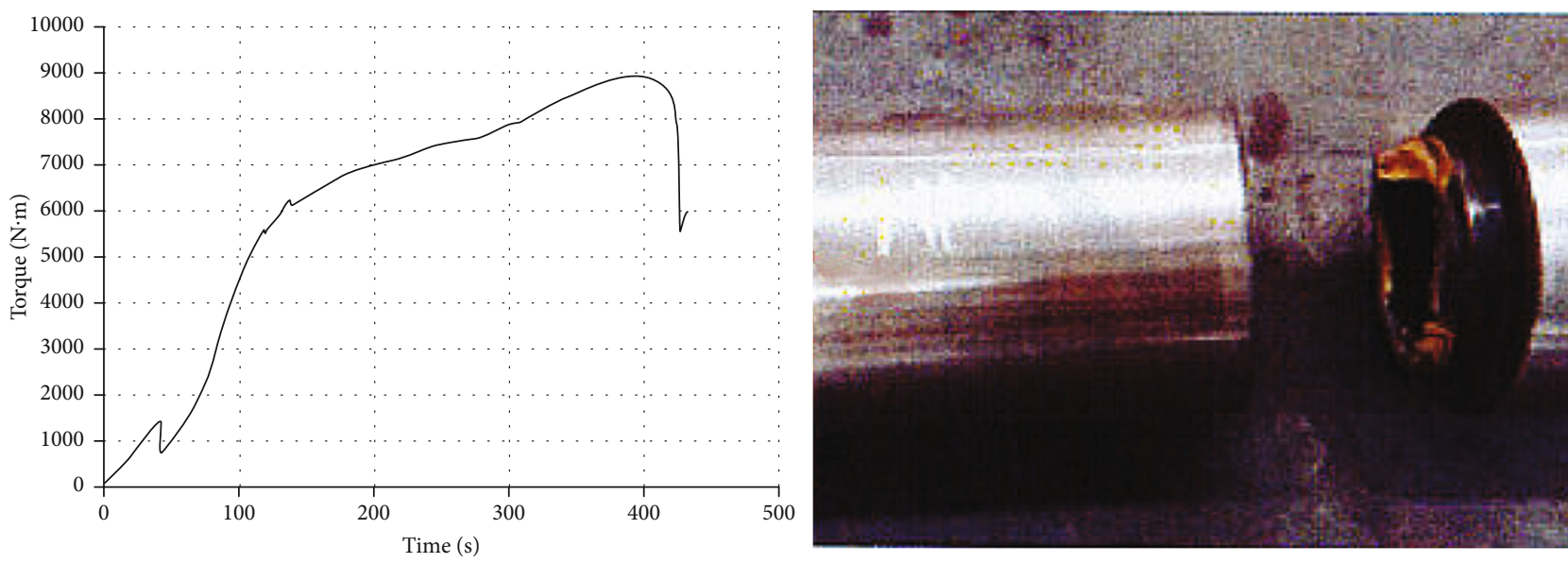

FIgURE 9: Torsion resistance test of the bionic drill pipe.

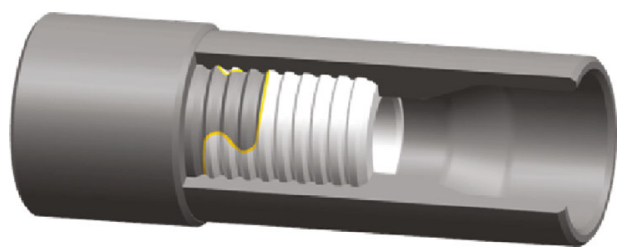

(a) Coupling model of bionic drill pipe joint

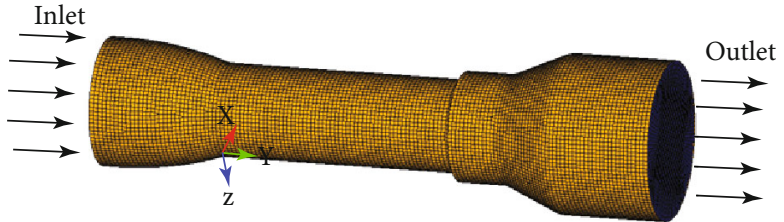

(b) Fluid domain model

Figure 10: Bionic drill pipe joint model and fluid domain model.

alloy material was filled, the tensile strength of the drill pipe was tested by the WAW-1000 hydraulic proportional control universal testing machine (Figure 8). The average tensile force was $555.48 \mathrm{kN}$, and the tensile strength of the drill pipe body met the performance requirements.

3.2. Torsion Resistance Testing. Torsion test on the outer joint of the bionic drill pipe was carried out by the torque test system (Figure 9). The average torsion breaking force was $8914.13 \mathrm{~N} \cdot \mathrm{m}$, and the torsion resistance of the bionic drill pipe joint met the performance requirements.

\section{Flow Field Performance Analysis of the Bionic Drill Pipe Joint}

Since the external joint of the bionic drill pipe is composed of three connecting components (the torsion shoulder, the front thread, and the cushion layer), when the drilling fluid is flowing, there may have the risk of fluid puncture and leakage on the connecting parts of the three components. So, the flow field numerical simulation is carried out, and the flow velocity and pressure distribution of the fluid are analyzed to illustrate the reliability of the flow field of the bionic drill pipe joint. 

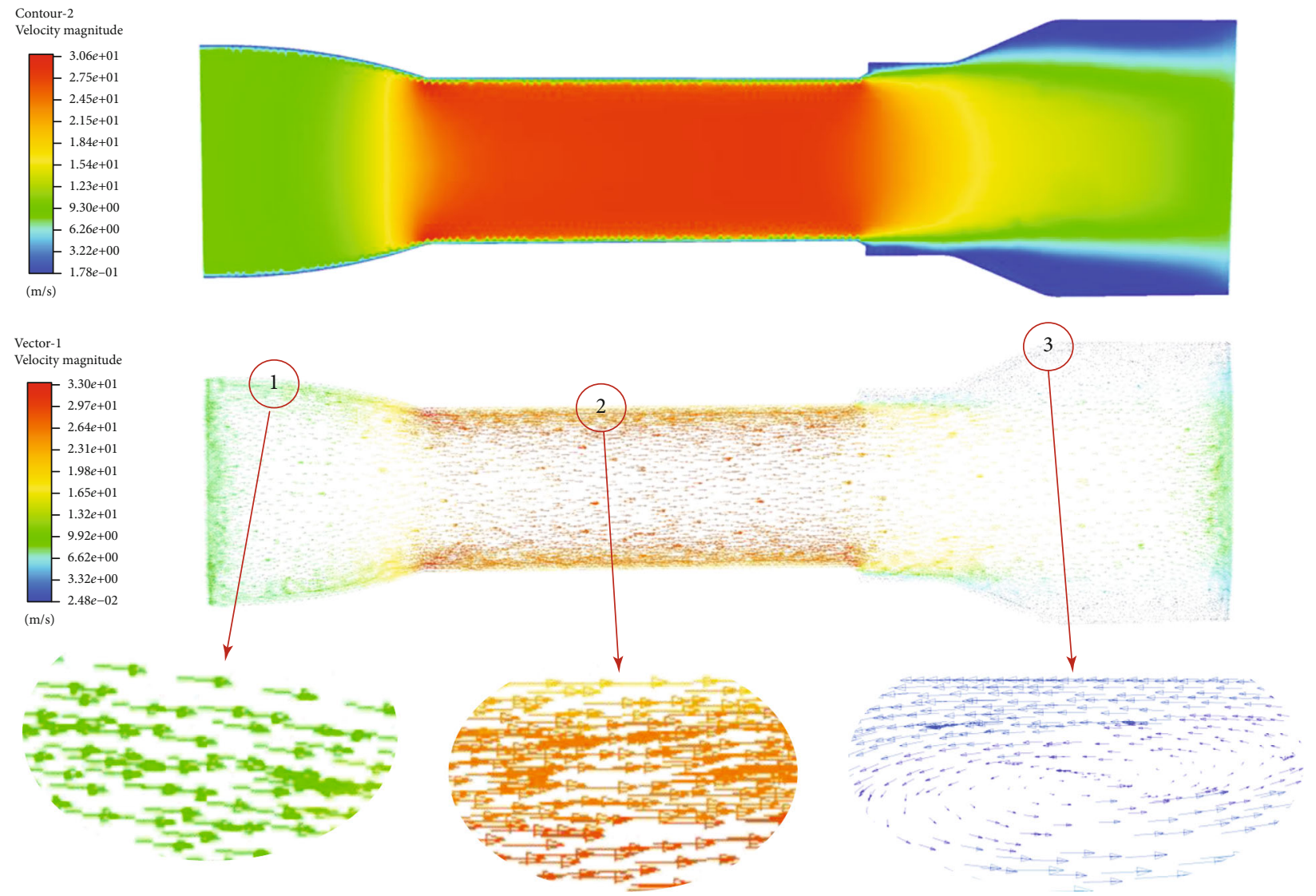

FIGURE 11: Cloud and vector diagrams of drilling fluid velocity in the axial cross section of the coupled model.

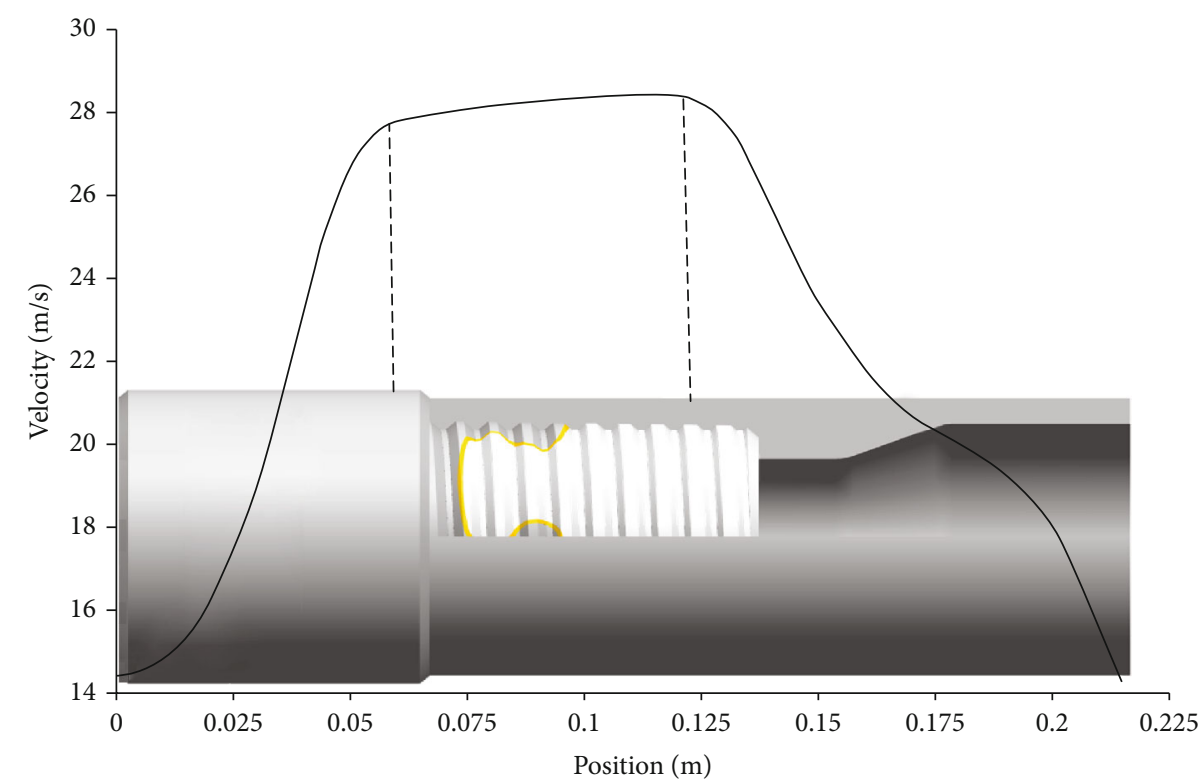

FIGURE 12: Velocity curve of drilling fluid along the central axis of the coupled model.

4.1. Numerical Model and Boundary Condition. The outer diameter of the drill pipe is $\varphi 73 \mathrm{~mm}$, and the diameter of the inner through-hole of the outer joint is $\varphi 23 \mathrm{~mm}$. Figure 10 shows the bionic drill pipe joint coupling model and the fluid domain model. In order to facilitate the numerical calculation, the fluid area is simplified, and the smaller chamfer at the mating surface is ignored to improve the quality of meshing. Tetrahedral elements are used to mesh the 


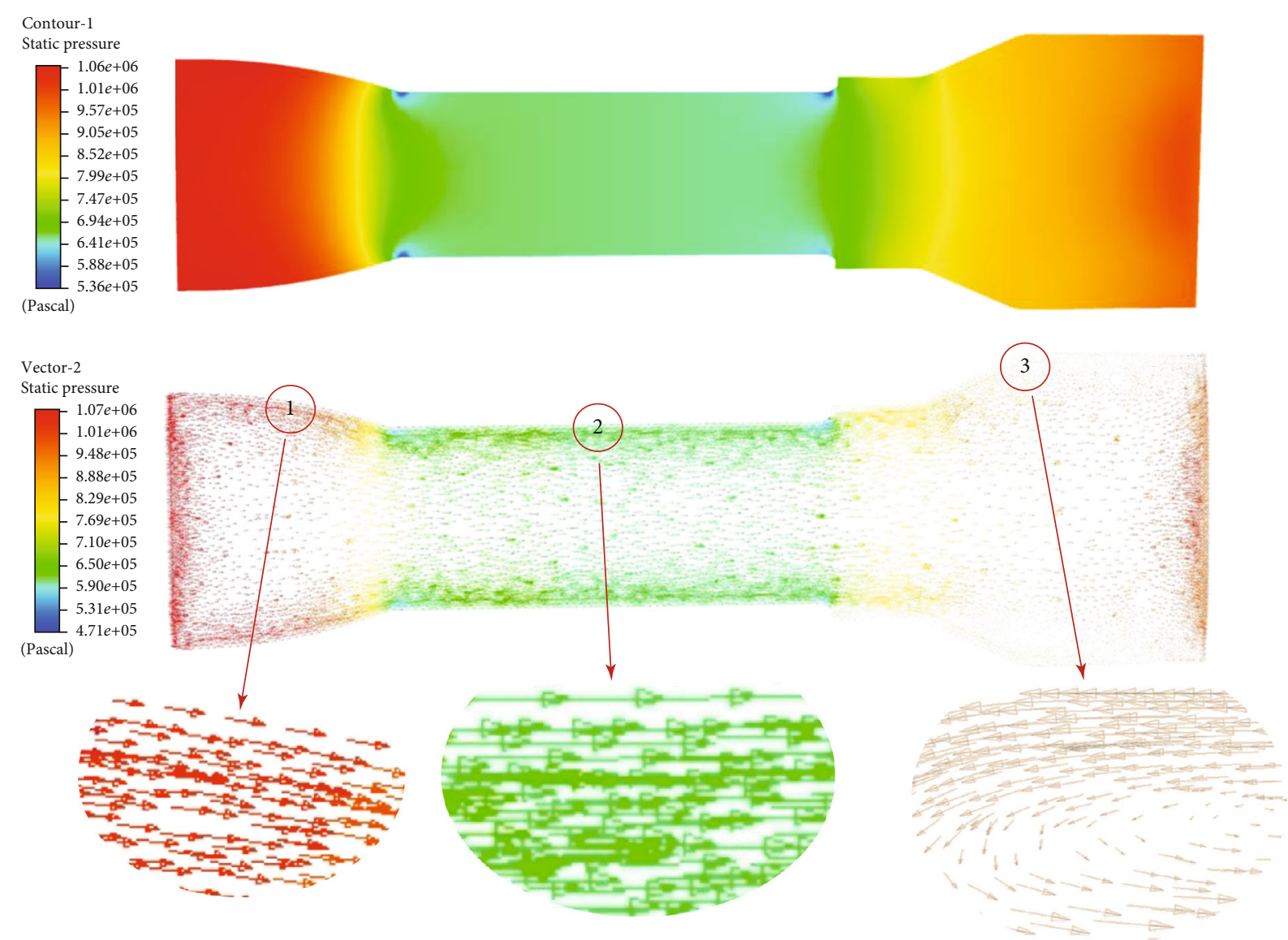

FIGURE 13: Drilling fluid pressure cloud diagram and vector diagram on the axis cross section of the coupled model.

model; in order to improve the calculation accuracy, the mesh size is set to $1 \mathrm{~mm}$. The specific meshing model is shown in Figure 10(b).

Setting the flow rate of the mud pump is $Q=25 \mathrm{~L} / \mathrm{s}$, the rotation speed is $n=100 \mathrm{rpm}$, the density of the drilling fluid is $\rho=1070 \mathrm{~kg} / \mathrm{m}^{3}$, the viscosity of the drilling fluid is $\mu=$ $0.00321 \mathrm{~kg} /(\mathrm{m} \cdot \mathrm{s})$, and the inner diameter of the drill pipe at the entrance is $d=47 \mathrm{~mm}$, so the flow velocity of the drilling fluid at the inlet boundary is $v=4 Q / \pi d^{2}=14.4 \mathrm{~m} / \mathrm{s}$.

The Reynolds number is used to judge the flow state of the drilling fluid in the drill pipe. The Reynolds number is calculated as $\operatorname{Re}=\rho v d / \mu=225600$, so the flow state of the drilling fluid is turbulent; turbulence intensity can be expressed as $I=0.16 \mathrm{Re}^{-1 / 8}=0.034$, turbulence scale is $l=0.07 d=$ $0.00329 \mathrm{~m}$, turbulent kinetic energy is $k=1.5(v I)^{2}=0.36 \mathrm{~m}^{2}$ $/ \mathrm{s}^{2}$, turbulence dissipation rate is $\varepsilon=C_{u}^{3 / 4}\left(k^{3 / 2} / l\right)=10.79 \mathrm{~m}^{2}$ $/ \mathrm{s}^{3}$ (where $C_{u}$ is an empirical constant, approximately 0.09).

According to the flow characteristics, the $k-\varepsilon$ turbulence model and the scaled wall function considering the roughness of the side wall are selected, the calculation is based on the pressure-based solver, and the least square interpolation calculation based on the element volume is used [19]. The inlet boundary condition is set as the velocity inlet, the outlet boundary condition is set as the pressure outlet, and the outlet pressure is set to $1.0 \mathrm{MPa}$.
4.2. Analysis of Simulation Results. Based on the symmetrical feature of the drill pipe joint structure, the simulation results are analyzed by intercepting the center cross section along the $Y$-axis of the coupling model.

Figure 11 shows the drilling fluid velocity cloud and vector diagram along the $Y$-axis center cross section of the bionic drill pipe coupling model. The drilling fluid enters the bionic joint from the left side at a velocity of $14.4 \mathrm{~m} / \mathrm{s}$. Due to the decrease in the cross-sectional area of the bionic joint, the flow rate of the drilling fluid increases. As the drilling fluid passes through the bionic joint area, the flow area increases gradually, and the flow rate of the drilling fluid decreases. From the velocity vector diagram, it can be seen that, during the process that the drilling fluid enters from the inlet and flows through the bionic joint, the drilling fluid flows steadily along the positive direction of $Y$, while when the drilling fluid passes through the bionic joint and enters into a larger cross section, the swirling vortex phenomenon occurs near the wall surface of the pipe, and the flow field is disturbed.

Figure 12 shows the curve of drilling fluid velocity variation on the central axis of the bionic drill pipe coupling model. The flow velocity of the drilling fluid in the flow channel corresponding to the bionic joint is relatively large, and the flow rate is gradually increasing. As the drilling fluid 
flows out of the bionic joint, the flow channel area increases and the flow rate of the drilling fluid decreases sharply. At the position where the drilling fluid whirlpool occurs (position no. 3 in Figure 11), the amplitude of the decrease of the drilling fluid flow rate slows down.

Figure 13 shows the drilling fluid pressure cloud diagram and vector diagram along the $Y$-axis center cross section of the bionic drill pipe coupling model. As the drilling fluid enters into the flow channel of the bionic joint from the inlet, the flow channel area decreases and the flow field pressure decreases. After the drilling fluid flows through the cross section of the bionic joint, the pressure of the flow field increases gradually until reaching the set outlet pressure value. As can be seen from the pressure vector diagram, in the process of drilling fluid flowing from the inlet into the bionic joint section, the pressure of the flow field is stable, while when the drilling fluid passes through the bionic joint and enters a larger flow cross section, pressure disturbance occurs on the wall of the pipe.

Through the simulation analysis, it can be seen that the drilling fluid flow field is stable at the bionic drill pipe joint, and there is no flow directed to the wall of the joint, which can effectively avoid the risk of leakage when the drilling fluid flows through the bionic drill pipe joints. Therefore, the flow performance of the designed bionic joint is reliable; the drilling fluid velocity field and pressure field are stable, which can meet the application requirements.

\section{Conclusions}

(1) Based on the principle of engineering bionics, the research on the bionic structure of drill pipe joints is carried out. For the bionic drill pipe joint, the fragile part of the root of the external thread is presplit into two parts: the torsion shoulder part and the front thread part, and then, the cushion layer is injected into the cutting seam between these two parts. Therefore, it is feasible to separate the torsion transmission function of the drill pipe joint from the connection function and realize the bionic effect of "breaking the bones and connecting the ribs"

(2) The processing and production of the bionic joint have been studied, and the test results of the bionic drill pipe joint show that the tensile performance can reach $555.48 \mathrm{kN}$, and the torsion resistance can reach $8914.13 \mathrm{~N} \cdot \mathrm{m}$, which can meet the performance requirements

(3) Flow field characteristics of the bionic drill pipe are analyzed through numerical simulation, simulation results show that the velocity field and pressure field of the fluid are stable, and there is no leakage phenomenon at the connecting components of the bionic joint

\section{Data Availability}

The data used to support the findings of this study are available from the corresponding author upon request.

\section{Conflicts of Interest}

The authors declare that they have no conflicts of interest.

\section{Acknowledgments}

This work was supported by the National Natural Science Foundation of China (42072345) and the Natural Science Foundation of Shaanxi Province (2021 JQ-952).

\section{References}

[1] M. Cao, Study on Fatigue Test and Life Prediction of Outer-Flat Drill Pipe for Drilling in Coal Mines, China Coal Research Institute, Beijing, 2014.

[2] W. H. Jiao, Fatigue Analysis of the Oil Drill Pipe Connection, East China University of Science and Technology, Shanghai, 2012.

[3] L. L. Dong, High Bending Bearing Drill Pipe Thread and Fatigue Behavior Research, Southwest Petroleum University, Nanchong, 2015.

[4] S. S. Li, L. Y. He, and S. P. Chen, "Failure analysis of thread fracture of drill pipe joint," Chinese Petroleum and Chemical Standards and Quality, vol. 40, no. 16, pp. 51-52, 2020.

[5] X. H. Meng, "Study on fatigue life prediction of drill pipe for mine drilling," Coal Science and Technology, vol. 48, no. 6, p. $148,2020$.

[6] S. J. Yu, D. M. Gong, M. Chen, and Z. Y. Ouyang, "Cause analysis of fracture of $42 \mathrm{CrMo}$ steel triangular spiral drill pipe joint," PTCA (Part A: PHYS. Test), vol. 56, no. 5, pp. 52-55, 2020.

[7] T. C. He, "Analysis of thread stress of oil drill and development of thread reduction coating," Xi' an University of Science Technology, Xi'an, 2019.

[8] D. Z. Tian, Y. Y. Chen, Q. Li, M. M. Dong, and P. Y. Mou, "Research status and prospect of drill pipe thread used in coal mine," Coal Geology \& Exploration, vol. 48, no. 4, pp. 233-239, 2020.

[9] Y. Liu, D. B. Li, C. J. Huang, Z. Q. Lei, and S. B. Li, "Structural optimization and element simulated of drill pipe threads," Mechanical Research \& Application, vol. 24, no. 2, pp. 25-27, 2011.

[10] D. X. Gao, D. Z. Zeng, H. B. Kang, B. Liu, J. Luo, and W. Ding, "Optimum design of double shoulder drill pipe joint," China Science Paper, vol. 15, no. 9, pp. 1044-1049, 2020.

[11] M. M. Dong, "Joint design and application of $\Phi 73 \mathrm{~mm}$ drill rod for large diameter and directional long borehole construction," Coal Mine Machinery, vol. 38, no. 5, pp. 113-116, 2017.

[12] G. Ke, S. Youhong, G. Runfeng, X. Liang, W. Chuanliu, and L. Yumin, "Application and prospect of bionic non-smooth theory in drilling engineering," Petroleum Exploration and Development, vol. 36, no. 4, pp. 519-541, 2009.

[13] H. Liu, Q. Yang, X. Pei et al., "Current status and development prospect of petroleum engineering bionics," Acta Petrolei Sinica, vol. 37, no. 2, pp. 273-279, 2016.

[14] R. J. Sun, S. C. Gu, X. B. Xie, K. Gao, and Y. Z. Zhang, "Research on bionic impact compacting bits," Coal Geology \& Exploration, vol. 46, no. 3, pp. 174-178, 2018.

[15] V. Harald, K. Daniel, F. Michael, and W. Sandro, "An efficient bionic topology optimization method for transversely 
isotropic materials," Composite Structures, vol. 204, pp. 359367, 2018.

[16] R. M. Alexander, N. J. Dimery, and R. F. Ker, "Elastic structures in the back and their role in galloping in some mammals," Proceedings of the Zoological Society of London, vol. 207, no. 4, pp. 467-482, 2010.

[17] D. X. Chen, Comparative Anatomical Atlas of Tiger, Leopard and Similar Animal Bones, China Medical Science Press, Beijing, 1995.

[18] Y. J. Zhou, Animal Anatomy, China Agricultural University Press, Beijing, 2007.

[19] X. Zhang, E. Zhai, Y. Wu, D.'a. Sun, and Y. Lu, “Theoretical and numerical analyses on hydro-thermal-salt-mechanical interaction of unsaturated salinized soil subjected to typical unidirectional freezing process," International Journal of Geomechanics, vol. 21, no. 7, article 04021104, 2021. 